\title{
Gaps between current clinical practice and evidence-based guidelines for treatment and care of older patients with Community Acquired Pneumonia: a descriptive cross- sectional study
}

Signe Eekholm ${ }^{1,3^{*}} \mathbb{D}$, Gerd Ahlström ${ }^{1}$, Jimmie Kristensson ${ }^{2}$ and Tove Lindhardt ${ }^{3}$

\begin{abstract}
Background: Community acquired pneumonia (CAP) remains a significant cause of morbidity and in-hospital mortality, and readmission rates are rising for older persons (> 65 years). Optimized treatment and nursing care will benefit patients and the health economy. Hence, there is a need to describe gaps between current clinical practice and recommendations in evidence-based guidelines for diagnostic procedures, medical treatment and nursing interventions for older patients with CAP.

Methods: Structured observations, individual ad hoc interviews and audits of patient records were carried out in an emergency department and three medical units. Data were analysed by manifest content analysis and descriptive statistics.

Results: Thirty patients (median age 74 years) admitted with CAP and 86 physicians, nurses, physiotherapists were included. The median length of stay (LOS) was 6.5 days, in-hospital mortality was 10 and $40.7 \%$ were readmitted within one month. The severity assessment tool (CURB-65) was used in $16.7 \%$ of the patients, correct antibiotic treatment prescribed for $13.3 \%$ and chest radiography ( $\leq 6$ weeks post-discharge) prescribed for $22.2 \%$. Fluid therapy, nutrition support and mobilisation plans were found to be developed sporadically, and interventions to be performed unsystematically and sparingly. Positive Expiratory Pressure therapy and oral care were the nursing interventions with lowest adherence, ranging from 18.2 to $55.6 \%$.

Conclusions: Adherence to recommendations was low for several central treatment and nursing care interventions for patients with CAP with possible consequences for patients and the use of resources. Thus, there is an urgent need to identify and remove barriers to adherence to recommendations in the neglected areas in view of the potential to improve patient outcomes.
\end{abstract}

Keywords: Community acquired pneumonia, Evidence-based guidelines, Adherence, Diagnosis, Treatment, Nursing care

\footnotetext{
* Correspondence: signe.eekholm@regionh.dk

'Department of Health Sciences, Faculty of Medicine, Lund University, P.O Box 157, SE-221 00 Lund, Sweden

${ }^{3}$ Research Unit for Clinical Nursing, Department of Internal Medicine, Copenhagen University Hospital Herlev and Gentofte, Herlev Ringvej 75, 2730 Herlev, Denmark

Full list of author information is available at the end of the article
}

(c) The Author(s). 2020 Open Access This article is distributed under the terms of the Creative Commons Attribution 4.0 International License (http://creativecommons.org/licenses/by/4.0/), which permits unrestricted use, distribution, and reproduction in any medium, provided you give appropriate credit to the original author(s) and the source, provide a link to the Creative Commons license, and indicate if changes were made. The Creative Commons Public Domain Dedication waiver (http://creativecommons.org/publicdomain/zero/1.0/) applies to the data made available in this article, unless otherwise stated. 


\section{Introduction}

There is a strong consensus worldwide that Community Acquired Pneumonia (CAP) remains a significant cause of morbidity and mortality and that the incidence is highest in older persons (> 65 years) $[1,2]$. In Denmark, CAP is the fifth most common cause of acute hospitalization among older patients ( $>67$ years) and the most common reason for readmission [3, 4]. In 2016, more than 31,500 older persons ( $>65$ years) were admitted to Danish hospitals with CAP and admission rates are rising at $1 \%$ per year [5] due to the overall increase in the older population [6]. Therefore, CAP represents a major cost and capacity challenge for hospitals and society.

Much effort has gone into developing national [7-11] and international [12-15] evidence-based guidelines (EBG) for diagnostic procedures, medical treatment and general management i.e. nursing care of patients with CAP, based on systematic review of scientific evidence and best practice. They are an important aid in translating scientific evidence into daily practice and have been developed to support healthcare professionals (HPs) in decision-making about appropriate and effective treatment and care for CAP patients [16]. An international cohort study [17] found that when HPs adhere to EBG for CAP, patient outcomes are significantly improved, with decreased length of hospital stay, in-hospital mortality and time to clinical stability. However, a Danish national cohort study [4] found large variations within regions and between hospitals in length of stay (LOS), in-hospital mortality, post-discharge mortality and readmission within 30 days.

This suggests an uneven and insufficient implementation of EBG. Based on these findings, a related study [18] investigated patient records $(n=100)$ of the same cohort from 20 hospitals across the country. They found that, while diagnostic procedures and medical treatment for CAP patients mainly concurred with EBG, no systematic plan for treatment or care was documented and general management recommendations for nutritional care, mobilisation and physiotherapy were neglected or only sporadically addressed. This represents a serious threat to patient safety $[19,20]$ indicating the need to improve the quality and effectiveness of treatment and care as well as the implemntation of evidence in practice $[21,22]$. Hitherto, the adherence to EBG for treatment and care of patients with CAP in national studies has been investigated mainly by audits $[4,18]$. However, as the lack of documentation is a well-described problem [18, 23], audits of patient records do not necessarily reflect the actual treatment and care. Hence, the possibility of evaluating the actual level of adherence to EBG by audit of patient records is limited [23], and observations of clinical practice are called for to identify gaps between current clinical practice and the recommendations in EBG for treatment and care of patients with CAP.
Aim

The aim of this study was to identify gaps between current clinical practice and evidence-based recommendations regarding diagnostic procedures, medical treatment and general management (nursing care interventions) for older patients admitted with CAP.

\section{Materials and methods Design}

This study had a descriptive cross-sectional design based on structured participant observations, individual ad hoc interviews during observations and audits of patient records. It is the first of four studies applying the systematic approach of implementation research [22] in which the first step is to investigate current clinical practice compared to the recommendations in EBG.

\section{Setting}

The study was conducted in a 957-bed university hospital in the capital region of Denmark that serves an area of 700,000 inhabitants providing specialist healthcare to approximately 174,000 patients per year. Patients who arrive at the hospital with suspected CAP are examined, diagnosed and stabilized in the emergency department (ED). The ED comprises a unit for internal medicine, staffed by nurses and physicians from the department of internal medicine covering various specialties. Stabilized patients in need of further treatment and care $(>24 \mathrm{~h})$, are transferred to one of three units (infectious diseases, respiratory diseases, or short-term unit) in the department of internal medicine, depending on which unit has a spare bed. On arrival from ED to the medical unit, the nurses assess the patients for individual care needs utilizing validated screening tools (e.g. functional level, nutritional status, etc.) [24] in order to develop individual treatment and nursing care plan. Regional guidelines require this plan to be made within $24 \mathrm{~h}$ of admission [8, $9,11]$. When reduced functional ability or malnutrition is identified, nurses need to develop care plans in cooperation with physiotherapists or dieticians. Likewise, the physicians assess each patient's response to the medical treatment and the microbiology results and modify it accordingly within 48-72 $\mathrm{h}$ of admission.

\section{Sample and recruitment}

Patients ( $\geq 65$ years) admitted with CAP and the staff who cared for them in the ED and the three medical units, were included prospectively and consecutively in the six months period of September 2016 to February 2017.

\section{Patient group}

In total, 50 patients were invited to participate the study. The sample was recruited in two phases: firstly, from the 
ED and secondly from the three medical units (MU). The inclusion process was managed by assessing the patient lists and patient records for eligible patients. At the ED, patients were selected at their arrival and if they had one or more of following symptoms: confusion, cough, expectoration, dyspnoea, fever, respiratory pain, tachypnoea, or lung crepitus. Inclusion was made when patients were diagnosed with CAP and given the ICD-10 code (International Statistical Classification of Diseases and Related Health Problems - Tenth Revision) DJ09.0DJ18.9. At the MU, patients were approached if they were $\geq 65$ years and diagnosed with CAP. Patients were excluded if they were not able to give informed consent (e.g. due to severe confusion) or had been diagnosed with chronic respiratory diseases (e.g. COPD, asthma etc.). Of 50 patients, one refused, four had severe confusion and 15 were excluded due to diagnosis with other respiratory diseases than CAP. The selection of the patients consisted of 30 patients ( $\geq 65$ years) admitted with CAP, $n=15$ patients from the ED and 15 patients from the MU (Fig. 1).

\section{Staff group}

The HPs in the selected units received information of the project at staff meetings and by the unit management's weekly newsletter. Once each patient was recruited the HPs who were treating and caring for them were identified and asked to participate. HPs had the right to refuse to participate in observations and interviews, but none did so. A total of 86 HPs (40 physicians, 40 nurses and 6 physiotherapists) delivered healthcare for the patients during the project period and were observed during the study.

\section{Data collection methods}

Data were collected through structured participant observations and individual ad hoc interviews, and through review of patient records. A data collection guide was developed for this study and structured according to the EBG criteria for diagnostic procedures, medical treatment and general management for patients with CAP [7-15], as shown in Additional file 1. General management i.e. nursing care interventions focused on: sputum mobilisation, oral care, fluids, nutrition, mobilisation and oxygen therapy, [7-15] all of which are central to nursing care and delivered by nurses.

In order to be able to identify if the relevant and sufficient treatment and care had been initiated in accordance with the patient's individual needs (i.e. adherence to EBG), patient needs were assessed independently of HP assessments by the researcher (SE), regarding the patient's hemodynamical and clinical status and according to the criteria in the EBG. This comprised specifically: identification of CURB65 score, travel exposure, relevance of sputum test and arterial blood gases, right choice of antibiotic treatment and all general management interventions (Additional file 1).

\section{Structured participant observations and individual ad hoc interviews}

The structured participant observations were carried out in two parts, following the data collection guide described above in order to identify gaps between current clinical practice and EBG recommendations regarding diagnostic procedures, medical treatment and general management interventions.

1) The first part took place in the ED, where the observation focus was on HPs' adherence to the guidelines for diagnostic procedures and acute treatment and care. Observations began at each patient's arrival to ED and ended when diagnosis was established, treatment plans made, and the medical treatment was initiated. The individual observations ranged between 6 and $8.5 \mathrm{~h}$.

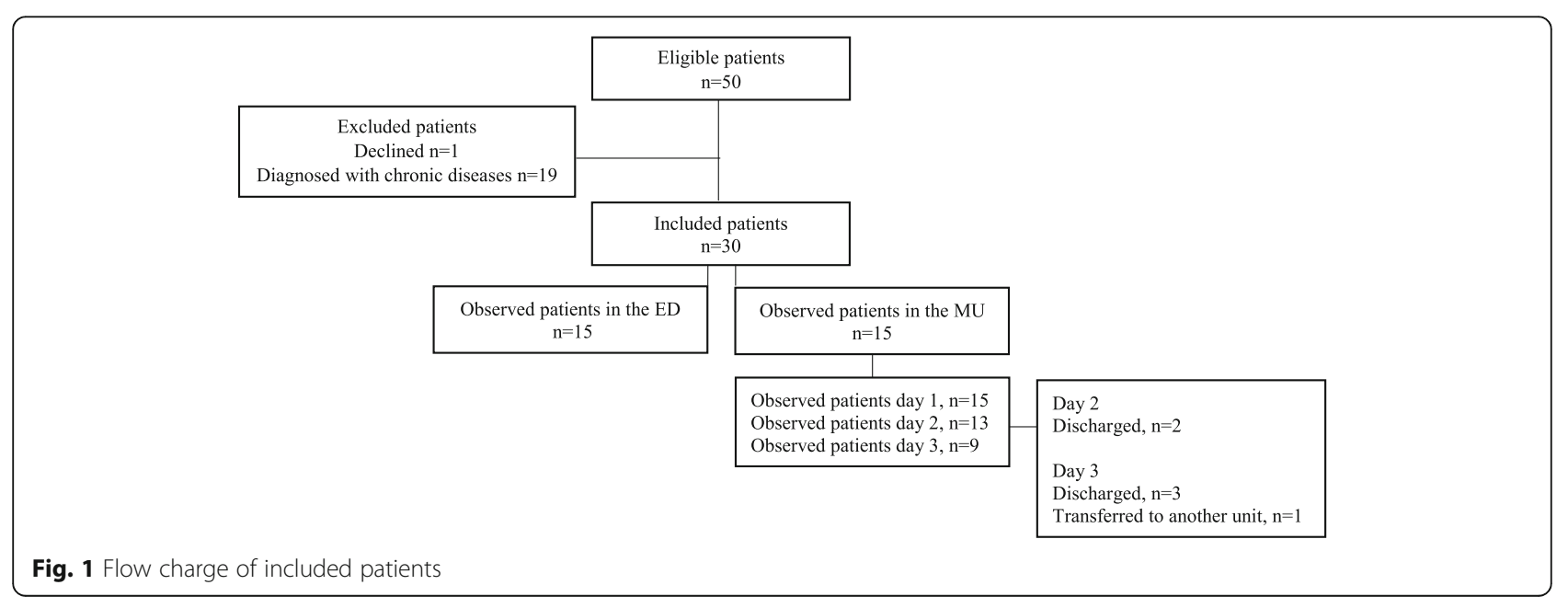


2) The second part was carried out in the MUs, with focus on nurses' adherence to recommendations for general management (nutrition, fluids, mobilisation, sputum mobilisation, and oral care management). The individual observations lasted from 07:30 to 19:00-21:00 for three days or until the patient was discharged, admitted to ICU or to another non-medical unit. For these reasons 15 patients were observed for one day, 13 for two days and 9 for three days (Fig. 1). In total, $528 \mathrm{~h}$ of observations were carried out. Field notes were continually written by hand during the observations in chronological order and included information about the date, time and the place of the observation, the context, the participants, verbatim verbal exchanges and researcher's personal reflections. Field notes were transcribed verbatim.

Individual ad hoc interviews with patients and HPs were conducted during observations in order to clarify any uncertainties. Notes were taken by hand during the interviews and transcribed verbatim as complementary data to the observational field notes. In total, 116 study participants (30 patients with CAP and 86 HPs) were interviewed.

\section{Patient record reviews}

Patient records were reviewed retrospectively according to a data collection guide to extract relevant variables including data for patient characteristics. This comprised: The Charlson Comorbidity Index [25] to calculate the impact of co-morbidities, the Cumulated Ambulation Score [26] assessing patients' basic mobility on admission and the CAP severity scoring system, CURB-65 score [13, 14] assessing the risk of mortality and severity of CAP. Further variables extracted from patient journals were: diagnostics procedures, medical treatment, discharge management and general management (Additional file 1). Furthermore, data for readmission, hospital mortality and mortality within 1 month of hospitalization were collected through patient records and data were recorded into a tally sheet created in a Word file (Additional file 2).

Credibility was aimed at by involving an experienced clinician and senior researcher (last author) in reflections at several key stages during the data collection period, as well as in all phases of the data analysis, challenging the first author's preunderstanding, choices and interpretations. The two additional authors participated in discussions and evaluation of the process at several stages of the data collection to decide whether any adjustments or changes were needed.

\section{Data analysis}

The transcribed field notes, interview texts and patient record reviews were analysed as one text body. Data were analysed by deductive, quantitative manifest content analysis [27]. The text was read through and coded according to analytic categories consisting of the criteria from the EBG. Each coding was given the value 0 or $1 ; 0$ being non-compliant and 1 being compliant with the respective criterion in the EBG. The SPSS version 25 software was used for descriptive statistics analysis.

To achieve a consistent approach, the first three transcribed texts were reviewed independently by all authors (SE, GA, JK, and TL). The deductive manifest analysis process was discussed until the authors reached a common understanding and agreement of the further analysis process. Both the first and last authors read all transcribed texts independently, wrote memos with reflections that were discussed and compared to reach a common understanding of the content. The first author (SE) independently established the manifest content and carried out the descriptive statistics, which was assessed and approved by the last author (TL).

The text was read through and coded according to analytic categories consisting of the criteria from the EBG. Each coding was given the value 0 or $1 ; 0$ being noncompliant and 1 being compliant with the respective criterion in the EBG. The SPSS version 25 software was applied to record the data for the use of descriptive statistics.

\section{Results}

\section{Patient characteristics}

The characteristics of the 30 patients included in the study are shown in Table 1 . The median age for the patients was 74 years and $16(53.3 \%)$ were males. The median level of co-morbidities was two. The most common findings at the admission were increased C-reactive protein in 28 patients (93.3\%), dyspnoea in 26 (86.7\%), cough in $25(83.3 \%)$ and sputum production in 25 (83.3\%). Nutritional deficiencies were presented in 23 (76.7\%) patients and 10 (33.3\%) were dependent on personal assistance because of decreased functional level. The CURB-65 score indicated that 13 (43.3\%) patients had moderate severity of CAP and 8 (26.7\%) had severe CAP and high risk of mortality. Two patients were discharged within $24 \mathrm{~h}$ of admission. The median length of hospitalization was 6.5 days and three (10\%) patients died while admitted. Of 27 surviving patients, 11 (40.7\%) were readmitted within one month. The incidence of 30 days mortality was $7.4 \%$.

\section{HP's adherence to diagnostic procedures regarding EBG criteria}

All 30 patients received: chest examinations to detect rales or bronchial breath sounds, oxygen saturation, electrolytes, C- reactive protein, full blood count, liver function test and mini-mental test (Table 2). Chest radiography was carried out for 28 (93.3\%) patients and 
Table 1 Characteristics of patients with CAP at admission to hospital $(n=30)$

\begin{tabular}{|c|c|}
\hline Diagnostic characteristics & $\begin{array}{l}\text { Frequency, } \mathrm{n}(\%) \\
\text { or median (IQR) }\end{array}$ \\
\hline Gender/male, & $16(53.3)$ \\
\hline Age, median (IQR) & $74(69.8-84.5)$ \\
\hline Smokers & $5(16.7)$ \\
\hline Penicillin allergy & $1(3.3)$ \\
\hline Cumulated Ambulation Score (CAS) $<6$ & $10(33.3)$ \\
\hline Charlson Comorbidity Index (CCI), median (IQR) & $2(1.0-3.0)$ \\
\hline Nutritional deficiencies, & $23(76.7)$ \\
\hline Fever $\left(\geq 38^{\circ} \mathrm{C}\right)$ & $13(43.3)$ \\
\hline C-reactive protein (> $10 \mathrm{mg} / \mathrm{L})$ & $28(93.3)$ \\
\hline Sputum production & $25(83.3)$ \\
\hline Dyspnoea & $26(86.7)$ \\
\hline Chills & $4(13.3)$ \\
\hline Pleuritic chest pain & $3(10.0)$ \\
\hline Confusion & $7(23.3)$ \\
\hline Pulse rate $>100$ & $13(43.3)$ \\
\hline Respiratory rate $\geq 30$ breaths/min & $4(13.3)$ \\
\hline Cough & $25(83.3)$ \\
\hline CURB-65 score: 0-1 points & $9(30.0)$ \\
\hline CURB-65 score: 2 points & $13(43.3)$ \\
\hline CURB-65 score: $\geq 3$ points & $8(26.7)$ \\
\hline Recent travel ( $\leq 2$ weeks) & $3(10.0)$ \\
\hline Responding to treatment $\leq 48 \mathrm{~h}$ & $20(71.4)^{\mathrm{a}}$ \\
\hline Length of hospital stay, median (IQR) & $6.5(3.0-14.3)$ \\
\hline In-hospital mortality & $3(10.0)$ \\
\hline Readmission $\leq 1$ month & $11(40.7)^{b}$ \\
\hline Post discharge mortality $\leq 1$ month & $2(7.4)^{b}$ \\
\hline
\end{tabular}

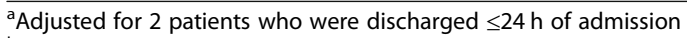
${ }^{\mathrm{b}}$ Adjusted for in-hospital mortality on 27 patients

$\mathrm{CCl}=$ Charlson Comorbidity Index is calculated based on 19 predefined comorbidities with assigned weights of 1,2,3, or 6 and summed to the total $\mathrm{CCl}$ score. $\mathrm{CAS}=$ Cumulated Ambulation Score is calculated by assessing 3 activities (1. getting in and out of bed, 2. sitting down and standing up from a chair, 3. walking ability with or without a walking aid) on a three-point scale ( $2=$ independent of human assistance or guidance, $1=$ requiring human assistance or guidance to perform activity, $0=$ unable to perform activity despite human assistance). The score for each activity is cumulated to provide a daily range from 0 to 6 . CAS score $<6$ indicates dependent of human assistance. CURB- $65=$ severity assessment score is calculated by giving 1 point for each of the following prognostic features: Confusion, Urea $>7 \mathrm{mmol} / \mathrm{l}$, Respiratory rate $>30$ breaths/minute, Low systolic $(<90 \mathrm{mmHg})$ or diastolic (< $60 \mathrm{mmHg}$ ) blood pressure, $\geq 65$ years. The total sum is stratified for CAP severity: (score 0-1) low severity; (score 2) moderate severity; (score 3-5) high severity

blood cultures for $26(86.7 \%)$ patients. Adherence to the recommended procedure was achieved regarding arterial blood gases in 24 of $26(92.3 \%)$ patients, sputum culture in 19 of $25(76.0 \%)$ and sensitivity test in 7 of 13 (53.8\%) patients respectively. The CURB-65 was applied in 5 (16.7\%) of the 30 patients. After $48 \mathrm{~h}$, two patients were stabilized and discharged. Of the 28 admitted patients, 8
Table 2 HPs' adherence to diagnostic tests regarding EBG criteria for patients with CAP

\begin{tabular}{|c|c|c|}
\hline $\begin{array}{l}\text { Diagnostic tests and tests for } \\
\text { non-responding patients }\end{array}$ & $\begin{array}{l}\text { Patients } \\
\mathrm{n}\end{array}$ & $\begin{array}{l}\text { Exposed for test, } \\
\mathrm{n}(\%)\end{array}$ \\
\hline \multicolumn{3}{|l|}{ Diagnostic tests: } \\
\hline Chest radiography & 30 & $28(93.3)$ \\
\hline Sputum test for culture and sensitivity & 25 & $19(76.0)^{\mathrm{a}}$ \\
\hline $\begin{array}{l}\text { Chest examination } \\
\text { (auscultation/percussion) }\end{array}$ & 30 & $30(100.0)$ \\
\hline Oxygen saturation & 30 & $30(100.0)$ \\
\hline Mini mental test & 30 & $30(100.0)$ \\
\hline Travel exposure anamnesis & 13 & $7(53.8)^{\mathrm{b}}$ \\
\hline \multicolumn{3}{|l|}{ Blood tests: } \\
\hline Blood cultures & 30 & $26(86.7)$ \\
\hline Full blood count & 30 & $30(100.0)$ \\
\hline C-reactive protein & 30 & $30(100.0)$ \\
\hline Electrolytes & 30 & $30(100.0)$ \\
\hline Liver function & 30 & $30(100.0)$ \\
\hline Arterial blood gases & 26 & $24(92.3)^{c}$ \\
\hline $\begin{array}{l}\text { Appliance of CURB-65 score to assess } \\
\text { disease severity }\end{array}$ & 30 & $5(16.7)$ \\
\hline Non-responding to treatment $\leq 48 \mathrm{~h}$ & 28 & $8(28.6)^{d}$ \\
\hline \multicolumn{3}{|l|}{ Tests for non-responding patients: } \\
\hline L. pneumophila urine antigen test, LUT & 8 & $1(12.5)$ \\
\hline Pneumococcal urine antigen test, PUT & 8 & $1(12.5)$ \\
\hline Polymerase chain reaction test, $\mathrm{PCR}$ & 8 & $3(37.5)$ \\
\hline Sputum test for culture and sensitivity & 8 & $1(12.5)$ \\
\hline C-reactive protein and white cell count & 8 & $8(100.0)$ \\
\hline Chest radiography & 8 & $7(87.5)$ \\
\hline Blood cultures & 8 & $7(87.5)$ \\
\hline
\end{tabular}

${ }^{a}$ Adjusted for patients with sputum

${ }^{\mathrm{b}}$ Adjusted for patients not able to travel

'Adjusted for patients with $\mathrm{SpO}_{2}<92 \%, \mathrm{RF}>20$ or dyspnoea

${ }^{\mathrm{d}}$ Adjusted for patients who were discharged $\leq 24 \mathrm{~h}$ of admission

(28.6\%) did not respond to the treatment within $48 \mathrm{~h}$. In repeated diagnostic procedures for non-responding patients' adherence was highest for C-reactive protein test, white cell count, chest radiography and blood cultures. Adherence was lowest for Polymerase Chain Reaction test (PCR), sputum test for culture and sensitivity, Legionella pneumophila urine antigen test and Pneumococcal urine antigen test.

\section{HP's adherence to medical treatment and discharge regarding EBG criteria}

The median time for intravenous antibiotic prescription was $165.5 \mathrm{~min}$ and $235.5 \mathrm{~min}$ to initiation of medication administration (Table 3). Antibiotics (AB) were prescribed in accordance with EBG recommendations for four (13.3\%) patients. Adjustment of $\mathrm{AB}$ treatment in accordance to pathogen resistance test $(\leq 48 \mathrm{~h})$ was reached in 22 
Table 3 HPs' adherence to antibiotic treatment and discharge management regarding EBG criteria

\begin{tabular}{|c|c|c|}
\hline $\begin{array}{l}\text { Antibiotic treatment } \\
\text { and discharge management }\end{array}$ & $\begin{array}{l}\text { Patients } \\
\mathrm{n}\end{array}$ & Adherence \\
\hline \multicolumn{3}{|l|}{ Antibiotic $(A B)$ treatment } \\
\hline $\begin{array}{l}\text { Time (minutes) to } \mathrm{AB} \text { prescription, } \\
\text { median (IQR) }\end{array}$ & 30 & $\begin{array}{l}165.5(127.3- \\
255.0)\end{array}$ \\
\hline $\begin{array}{l}\text { Time (minutes) to } A B \text { administration, } \\
\text { median (IQR) }\end{array}$ & 30 & $\begin{array}{l}235.5(187.0- \\
401.0)\end{array}$ \\
\hline $\begin{array}{l}A B \text { treatment prescribed in accordance } \\
\text { with EBG criteria, } n(\%)\end{array}$ & 30 & $4(13.3)$ \\
\hline $\begin{array}{l}\text { Adjustment of } A B \text { treatment } \leq 48 \mathrm{~h} \text { of } \\
\text { admission, } \mathrm{n}(\%)\end{array}$ & 28 & $22(78.6)^{a}$ \\
\hline $\begin{array}{l}\text { Switch from intravenous to oral } A B \\
\text { treatment } \\
\text { in accordance with EBG criteria, } n(\%)\end{array}$ & 20 & $15(75.0)^{b}$ \\
\hline \multicolumn{3}{|l|}{ Discharge management } \\
\hline $\begin{array}{l}\text { Prescription of } 6 \text { weeks polyclinical } \\
\text { control, } n(\%)\end{array}$ & 27 & $21(77.8)^{c}$ \\
\hline $\begin{array}{l}\text { Prescription of chest radiography } \\
\text { ( } \leq 6 \text { weeks post-discharge), } \mathrm{n}(\%)\end{array}$ & 27 & $6(22.2)^{c}$ \\
\hline
\end{tabular}

${ }^{a}$ Adjusted for patients who were discharged $\leq 24 \mathrm{~h}$ of admission

${ }^{\mathrm{b}}$ Adjusted for patients who responded to treatment $\leq 48 \mathrm{~h}(n=20)$

'Adjusted for in-hospital mortality ( $n=27$ surviving patients)

(78.6\%) cases. The expected response to treatment within $48 \mathrm{~h}$ occurred in 20 (71.4\%) cases (Table 1), and the recommended switch from intravenous antibiotic treatment to oral treatment within $48-72 \mathrm{~h}$ for responding patients was carried out in 15 (75.0\%) cases (Table 3). The six weeks clinical control was prescribed in 21 (77.8\%) cases. Control chest radiography was required in all cases but prescribed in six (22.2\%).

\section{HP's adherence to general management regarding EBG criteria}

Of the 11 patients who fulfilled the EBG for sputum mobilization support, two (18.2\%) patients received it by Positive Expiratory Pressure (PEP) on the first observation day and three (42.9\%) patients on the third observation day (Table 4). Oral care was delivered twice a day to four $(26.7 \%)$ patients on the first day of observation, three $(23.1 \%)$ on the second and five (55.6\%) on the third observation day. Of ten patients who needed fluid therapy, the fluid therapy plan was developed for nine (90.0\%) patients on the first observation day, eight $(88.9 \%)$ on the second day, and six $(85.7 \%)$ on the third observation day. Of those patients, four received fluid therapy according to their plan during the first and last observation days and two $(25.0 \%)$ on the second observation day. Of the total sample, eight patients were screened for nutritional status, four of them within $24 \mathrm{~h}$ of admission. Eleven (73.3\%) patients fulfilled the EBG criteria for nutritional support at the first observation, nine $(69.2 \%)$ at the second and seven $(77.8 \%)$ on the third day. In total, a nutritional support plan was developed for six patients. Due to lack of documentation of energy and protein needs for all patients included from MU, and insufficient registration of nutritional intake in the patient journals it was not possible to assess whether patients received nutrition in accordance with their needs. Mobilisation $\geq 20$ min was achieved for 11 (73.3\%) patients during the first observation day, eight (61.5\%) during the second day and five (55.6\%) during the third. For patients needing mobilisation support, a mobilisation plan was developed for six $(60.0 \%)$ patients at the first and the last observation day, and for seven (75.0\%) patients during the second day. Two (33.3\%) patients were mobilised according to their individual mobilisation plan on the first observation day, three $(42.9 \%)$ on the second day and three (50.0\%) on the third. Oxygen therapy was delivered according to recommended criteria in EBG for eight $(88.9 \%)$ patients during the first observation day and $100.0 \%$ during subsequent observation days.

\section{Discussion}

The aim of this study was to identify gaps between current clinical practice and EBG recommendations regarding diagnostic procedures, medical treatment and general management for older patients with CAP. We identified a few, but potentially serious gaps in diagnostic procedures and medical treatment, as well as in general management, all of them with possible impact on patient outcomes and safety.

\section{Diagnostic procedures and medical treatment}

Among diagnostic procedure recommendations, the severity assessment score CURB-65 was rarely used within the units included in this study. This result is consistent with previous national and international research findings [18, 28-30]. Initial assessment of illness severity is considered to be one of the most important steps in the management of older patients admitted with CAP [7, 11-14]. It supports HPs in determining patient needs at admission, site of care, the extent of diagnostic testing and in choosing the appropriate antibiotic treatment, all of which are independent factors with impact on CAP patient morbidity and mortality [7, 11-14]. Our results and previous studies indicate that CURB-65 is not routine practice in hospital settings and tailored implementation strategies are needed [22] to achieve higher adherence rates for the benefit of patient safety and the health economy.

Among medical treatment procedures, the initial choice of antibiotics was the intervention that was least frequently carried out according to recommendations. Presumably, this is a consequence of the low prevalence of severity assessment, as the initial choice of antibiotic 
Table 4 HPs' adherence to EBG recommendations for general management in three medical units*

\begin{tabular}{|c|c|c|c|}
\hline General management & $\begin{array}{l}\text { Observation day } 1 \text {, Patients in } \\
\text { need / Patients receiving } \\
\text { treatment, } \mathrm{n} / \mathrm{n}(\%)\end{array}$ & $\begin{array}{l}\text { Observation day } 2 \text {, Patients in } \\
\text { need / Patients receiving } \\
\text { treatment, } \mathrm{n} / \mathrm{n}(\%)\end{array}$ & $\begin{array}{l}\text { Observation day } 3 \text {, Patients in } \\
\text { need / Patients receiving } \\
\text { treatment, } \mathrm{n} / \mathrm{n}(\%)\end{array}$ \\
\hline \multicolumn{4}{|l|}{ Sputum mobilisation } \\
\hline In need of sputum mobilisation & 15/11 (73.3) & $13 / 10(76.9)$ & 9/7 (77.8) \\
\hline $\begin{array}{l}\text { Sputum mobilisation received } \\
\text { by PEP' }\end{array}$ & $11 / 2(18.2)$ & 10/2 (20.0) & $7 / 3(42.9)$ \\
\hline \multicolumn{4}{|l|}{ Oral care } \\
\hline Oral care (twice a day) & $15 / 4(26.7)$ & $13 / 3(23.1)$ & $9 / 5(55.6)$ \\
\hline \multicolumn{4}{|l|}{ Intravenous fluid therapy } \\
\hline In need of fluid therapy & $15 / 10(66.7)$ & $13 / 9(69.2)$ & 9/7 (77.8) \\
\hline Fluid therapy plan developed ${ }^{\mathbf{c}}$ & $10 / 9(90.0)$ & 9/8 (88.9) & $7 / 6(85.7)$ \\
\hline $\begin{array}{l}\text { Fluids received accordance to fluid therapy } \\
\text { planc }^{c}\end{array}$ & $9 / 4(44.4)$ & $8 / 2(25.0)$ & $6 / 4(66.7)$ \\
\hline \multicolumn{4}{|l|}{ Nutrition support } \\
\hline Screening for nutrition status ( $\leq 24 \mathrm{~h}$ ) & $15 / 4(26.7)$ & 13/4(30.8) & $9 / 4(44.4)$ \\
\hline $\begin{array}{l}\text { Screening for nutrition status (up to or } \\
\text { during observation days) }\end{array}$ & $15 / 8(53.3)$ & $13 / 8(61.5)$ & 9/8 (88.9) \\
\hline In need of nutrition support & 15/11 (73.3) & $13 / 9(69.2)$ & 9/7 (77.8) \\
\hline $\begin{array}{l}\text { Development of nutrition support } \\
\text { plan }^{d, b}\end{array}$ & $11 / 6(54.5)$ & $9 / 6(66.7)$ & $7 / 6(85.7)$ \\
\hline \multicolumn{4}{|l|}{ Mobilization } \\
\hline $\begin{array}{l}\text { Mobilization (walk or sit out of } \\
\text { bed } \geq 20 \mathrm{~min} \text { ) }\end{array}$ & 15/11 (73.3) & $13 / 8(61.5)$ & $9 / 5(55.6)$ \\
\hline In need of mobilisation support & $15 / 10(66.7)$ & 13/10 (76.9) & $9 / 8(88.9)$ \\
\hline Development of mobilisation plan ${ }^{e, b}$ & $10 / 6(60.0)$ & 10/7 (70.0) & $8 / 6(75.0)$ \\
\hline $\begin{array}{l}\text { Mobilization received accordance to } \\
\text { mobilisation plane }\end{array}$ & $6 / 2(33.3)$ & $7 / 3(42.9)$ & $6 / 3(50.0)$ \\
\hline \multicolumn{4}{|l|}{ Oxygen therapy } \\
\hline In need of oxygen therapy & $15 / 9(60.0)$ & $13 / 9(69.2)$ & 9/8 (88.9) \\
\hline $\begin{array}{l}\text { Oxygen therapy initiated and } \\
\text { monitored according to } \mathrm{SpO}_{2} \text { level }\end{array}$ & 9/8 (88.9) & 9/9 (100.0) & $8 / 8(100.0)$ \\
\hline
\end{tabular}

averall, 15 patients were observed day 1, 13 patients day 2 and 9 patients day 3 . Results are expressed as a number of patients expected to receive the intervention and the number of patients who received it

${ }^{\mathrm{a}-\mathrm{e}}$ Test is adjusted for patients in need of: a) oxygen therapy; b) sputum mobilisation; c) intravenous fluid therapy; d) nutrition support; e) mobilisation plan ${ }^{b}$ Care plan was not developed according to EBG but was accepted because it described some sort of plan for patient, although incomplete and unsystematic

treatment should be guided by the CURB-65 score [7, 11-14]. Appropriate antibiotic prescription in hospitals ensures effective treatment of patients and administration of appropriate antibiotics within $4-8 \mathrm{~h}$ is associated with $5-43 \%$ relative reduction in mortality $[31,32]$. Inappropriate antibiotic therapy, on the other hand, is an independent predictor of in-hospital and 30-day mortality and associated with morbidity and increased treatment costs [31, 33-35]. Regrettably, inappropriate antibiotic treatment is common, both when it concerns the initial choice of $\mathrm{AB}[36,37]$ and treatment targeted the identified pathogen [33]. A Cochrane review [38] finds strong evidence for the effect on compliance of interventions that support physicians in prescribing the appropriate treatment (e.g. procedural instructions, feedback and stewardship). Further effects were reduced duration of antibiotic treatment by 1.95 days (95\% CI 2.22 to 1.67 ) and length of stay by 1.12 days (95\% CI 0.70 to 1.54$)$.

Timely switch from intravenous to oral antibiotic treatment was seen in most cases in our study. Early switch of antibiotic treatment not later than the third day may reduce the iatrogenic events and LOS by 3.4 days [39, 40]. Importantly, a quarter of our sample were not switched to oral treatment in time despite clinical and haemodynamical stability as recommended in EBG [7, 11-14], with possible consequences for patient safety and economy [39]. Therefore, there is also a need to identify barriers to early switching and to develop a tailored strategy for the implementation of an intervention that facilitates timely switching to oral treatment. 
More than a quarter of the patients in our study did not respond to treatment within the expected time frame, and a systematic diagnostic approach for nonresponding patients was limited. It is common to find patients not responding to treatment, and mortality rates for those patients are reported as high as 49\% [13]. Therefore, it is strongly recommended to reassess nonresponding patients' treatment and to perform multiple relevant diagnostic tests to determine specific respiratory pathogens, in order to permit prescription of appropriate antibiotic treatment [7, 11-14]. According to Arancibia et al. [41] a systematic diagnostic approach by invasive, non-invasive, and imaging procedures can lead to a specific diagnosis in $73 \%$ of cases. Hence, a systematic and evidence-based approach to avoid treatment failure and reduce the rate of in-hospital mortality seems warranted.

\section{General management}

General management i.e. nursing care interventions, performed by nurses in our study, are vital for patients with CAP as they are reported to have reduced morbidity, mortality, LOS and readmission rates [15, 42-51].

The only nursing care intervention that was performed systematically in our study was oxygen therapy, whereas sputum mobilisation by PEP and oral care were carried out less frequently. Previous studies have identified that PEP treatment can reduce fever duration and length of hospital stay [42, 48] and oral care in critically ill patients is associated with 18 to $24 \%$ of reduction in the odds of developing ventilator-associated pneumonia [51], while low adherence to oral care has consequences such as pain, malnutrition, readmissions, increased healthcare costs and mortality $[10,46,51]$. Therefore, special attention should be paid to sputum mobilisation and oral care to achieve better adherence among HPs, in order to deliver effective and safe treatment for patients with CAP.

Despite plans for fluid therapy made for most patients in our study, adherence to planned interventions were rare and unsystematic, which can put the patient at risk of renal and electrolyte complications. According to Guppy et al. [52] the incidence of hyponatremia is common for patients with infections of the lower respiratory tract and $10.5 \%$ of CAP patients have been identified as developing hyponatremia during hospitalization. Those results indicate the need to focus on fluid therapy when designing a strategy to implement evidence-based practice for patients with CAP.

The majority of the patients in our study were at nutritional risk but, as nutrition support plans were either lacking, or at best insufficient (e.g. missing calculation of individual needs for energy and protein for all $30 \mathrm{pa}-$ tients), the nurses could not assess the sufficiency of the patients' intake nor could the researchers assess HPs' adherence to recommendations for nutrition support. Therefore, adherence to nutrition support needs to be determined with further research.

In our study, more than half of the patients were mobilised $20 \mathrm{~min}$ or more. Noting that EBG strongly recommend $20 \mathrm{~min}$ mobilisation within $24 \mathrm{~h}$ of hospitalisation and increase of mobilisation each subsequent day, our results indicate that approximately a quarter of the patients were mobilised less than recommended. Even though mobilisation plans were frequently developed, activities according to mobilisation plans were less frequently performed. Those results are consistent with other studies reporting that older patients with CAP may be at risk of functional loss during hospitalisation and after discharge, due to insufficient mobilisation [20, 53]. Considering that regular mobilisation reduces functional decline, mobilisation should be encouraged for older patients with CAP during hospitalisation [54]. Moreover, studies of CAP demonstrate that early mobilisation is safe and effective in reducing length of hospital stay $[45,55]$.

To deliver effective and targeted nursing care interventions, a systematic assessment of patient individual needs and development of an individual nursing care plan is essential [7-15]. In our study, nursing care plans were found to be scarce and unsystematically developed (e.g. missing data on patient status, developed only partly, intervention or duration of the intervention not described according to EBG recommendations). This supported previous finding by Lindhardt et al. [18] who found care planning for patients with CAP to be rare and unsystematic and nursing documentation insufficient. Jones et al. [47] identified also nursing care planning to be among the top five most frequently incomplete activities in nursing practice. On the other hand, an observational study by De Marinis et al. [23] has reported that only $40 \%$ of nursing activities are consistent with the documentation as nurses perform more activities than they report. This result is supported by findings from the recent systematic review [56] that found nursing care planning to be more often missed than performance of nursing care. The level of missed nursing care associated with adverse patient outcomes is high, with an overall estimate of $88 \%$ in acute hospitals in Europe [56]. The association between nursing care planning and the level of interventions performed was not under investigation in our study but deserves more specific attention in future studies.

The lack of systematic care planning and management of described interventions constitutes a threat to patient safety. Nevertheless, our findings are not breaking news as the phenomenon of missing care, defined as any aspects of care that is omitted or delayed, in part or in whole [56], is a comprehensive problem nationally and internationally with a prevalence of $55-98 \%$ in acute 
care hospitals $[47,49,50]$. Seemingly, among all the EBG recommendations in our study, nurses had more difficulties adhering to EBG than the physicians. Due to the scope of the study, the cause of the low adherence is unknown and needs further investigation in future studies. Other studies have identified staffing, time scarcity, resources, inadequate support from peers, professional behaviour, knowledge and culture as some of the factors that could influence HPs' adherence to EBG [34, 56-58]. Further, the insufficient and inadequate description of nursing interventions in the EBG for treatment and care of CAP could also be considered a barrier to nurses' adherence to EBG recommendations. While national and international EBG for CAP thoroughly review diagnostic tools and choice of antibiotic treatment, they do not emphasise the importance of nursing care interventions and the consequences of missed care. Considering the impact of nursing interventions for patient recovery and safety $[59,60]$, the absence of description of nursing interventions in EBG constitutes a threat to successful patient outcome. Therefore, the revision of the EBG should be considered. However, our results indicate that even if diagnostic procedures and medical treatment are well described in the EBG, only a fraction of these guidelines have been implemented in clinical practice. This could indicate that even a thorough description of nursing interventions in the EBG may not increase the adherence rate. Instead, according to implementation researchers $[21,22]$ factors influencing HPs adherence to EBG should be focused on in order to promote the successful uptake of research findings into routine practice and improve the quality and effectiveness of treatment and care. Implementation science emphasizes that factors influencing HPs' adherence to EBG can be linked to both individual, team and organizational level and are related to the context where the treatment and care is performed [22, 61]. The context is recognized as a core factor that influences implementation [22, 62]; thus, it is important to identify contextual barriers hindering, and facilitators supporting HPs in performing evidence-base practice. This is considered a fundamental criterion for successful implementation as this knowledge is crucial for the development of tailored and contextoriented implementation strategies targeting the problem areas [21, 22, 63].

\section{Methodological considerations}

The strength of this study was the triangulation of research methods [64] where observations, interviews and data from patient records allowed us to reveal different perspectives of a research question and helped us to achieve better understanding of the real-life management of older patients with CAP in a hospital setting. Particularly, individual ad hoc interviews were helpful to complete the data collection, as interviews revealed uncertainties that were not possible to clarify by observations or by audits, e.g. clarification of whether assessment of CURB-65 had taken place, or whether oral care had been carried out. We also acknowledge the limitation that all data were collected by a single researcher. Observations were carried out only by the first author as the presence of several observers could have affected the natural context for HPs and intimidated both them and the patients. The first author is a registered nurse with many years of professional experience, including the care of CAP patients and had a preunderstanding of the context that was required to analyse and collect data in a complex setting by multiple methods. However, this inside perspective and preunderstanding can be perceived both as a methodological strength and limitation. To enhance credibility, all authors were involved in reflections and discussions throughout the data collection period, analysis and evaluation of the project to challenge the first author's preunderstanding, choices and interpretations.

To identify HPs' adherence to EBG recommendations, the researcher had to make her own assessment of each patient's condition and needs. The conclusion reached in the assessment of the patient may therefore differ from that of the HPs. However, researcher's assessment of patient conditions and needs was guided by the EBG and as such are expected to be followed by the HPs. To increase the credibility, the last author rechecked the first author's assessment of patient individual needs according to EBG criteria and patient's clinical data. Furthermore, after transformation of qualitative data to quantitative data, all numerical data were rechecked according to the content in transcribed text. After entering data into SPSS, all data were rechecked three times before performance of any statistics. It is also worth noting that the study was carried out in a single hospital and the sample size for participating patients was small; hence, the transferability of the findings may be limited as the study may be context-specific.

\section{Conclusion}

Our results indicate that HPs adherence for recommended EBG criteria for treatment and care of patients with CAP was low for several central interventions. To improve patient outcomes, and to ensure that patients receive evidence-based treatment and care, there is a need to focus on severity assessment score, correct antibiotic treatment, diagnostic procedures for non-responding patients and, particularly, on nursing care interventions. Considering described gaps, future research needs to identify barriers to EBG criteria and take them into account when implementing evidence-based clinical practice in a hospital setting. 


\section{Supplementary information}

Supplementary information accompanies this paper at https://doi.org/10. 1186/s12879-019-4742-4.

Additional file 1. Recommended interventions for older patients admitted with CAP

Additional file 2. Tally sheet for registration

\section{Abbreviations}

AB: Antibiotic; BMI: Body mass index; CAP: Community acquired pneumonia; CAS: Cumulated Ambulation Score; CCl: Charlson Comorbidity Index; CRP: Creactive protein; CURB-65: Severity assessment score; EBG: Evidence-based guidelines; ED: Emergency department; HPs: Healthcare professionals; ICD10: International Statistical Classification of Diseases and Related Health Problems - Tenth Revision; LOS: Length of stay; LUT: Pneumococcal urine antigen test; MU: Medical units; PCR: Polymerase chain reaction test

\section{Acknowledgments}

We thank Copenhagen University Hospital for research access and healthcare professionals and patients for their willingness to participate in a study.

\section{Authors contributions}

SE designed the study which was approved by GA, JK, TL and Lund University. SE was responsible for the patients' recruitment, inclusion, data collection and analysis. SE wrote the manuscript and all authors reviewed and approved the final manuscript.

\section{Funding}

SE received a salary from the Copenhagen University Hospital Herlev and Gentofte, without any impact on design, collection, analysis and interpretation and writing of the manuscript.

\section{Availability of data and materials}

All data generated and analysed during this study are included in this published article.

\section{Ethics approval and consent to participate}

The study was conducted in compliance to the Helsinki declaration [65] and was approved by the Danish Ethical Committee (Pr. No. H-16018863) and in accordance with the Danish Data protection Agency (J. No. HGH-2016-062). Patients and their relatives received both written and verbal information about the project. Patients and their relatives were informed that the staff and their clinical practice were being observed and that, if they agreed to participate, the researchers would also need to collect data from their patient records. Patients were informed that participation was voluntary and that they could withdraw at any time without giving any reasons. Participants were given time to consider participation with the possibility of asking questions about the study. Patients who agreed to participate gave written informed consents for their participation.

The project was initiated upon request from the head nurse and chief physician of the department of internal medicine, who also approved the researchers' access to the units and their data. HPs were informed about the voluntary aspect of participating and that the data and study results would be treated confidentially and in accordance with data protection law. In case of signs of severe deterioration, which might put the patient at risk during the observations, the researcher (SE) terminated the observations and intervened by informing HPs about the inadequate procedure. This was required in three cases, all of them on the last observation day, which made it acceptable to include them in the material. In the cases when the patients were not informed about oral care, mobilisation, nutrition support, daily fluids intake or sputum mobilisation, the researcher informed the involved HPs and CAP patients after final observations. This was required in all 30 cases.

\section{Consent for publication}

Not applicable.

\section{Competing interests}

The authors declare that they have no competing interests.

\section{Author details}

'Department of Health Sciences, Faculty of Medicine, Lund University, P.O. Box 157, SE-221 00 Lund, Sweden. ${ }^{2}$ Department of Health Sciences, Lund University, P.O. Box 157, SE-221 00 Lund, Sweden. ${ }^{3}$ Research Unit for Clinical Nursing, Department of Internal Medicine, Copenhagen University Hospital Herlev and Gentofte, Herlev Ringvej 75, 2730 Herlev, Denmark.

Received: 24 March 2019 Accepted: 27 December 2019

Published online: 23 January 2020

\section{References}

1. Feldman C, Anderson R. Community-acquired pneumonia: still a major burden of disease. Curr Opin Crit Care. 2016;22(5):477-84.

2. Chong CP, Street PR. Pneumonia in the elderly: a review of the epidemiology, pathogenesis, microbiology, and clinical features. South Med J. $2008 ; 101(11): 1141-5$

3. The Danish Health Authority. In: Readmission of elderly in Denmark in 2008 The Danish Health Authority 2009. http://www.sst.dk/Udgivelser/2009/ Genindlaeggelser\%20af\%20aeldre\%20i\%20Danmark\%202008.aspx. Accessed 1 Feb 2019.

4. Klausen HH, Petersen J, Lindhardt T, Bandholm T, Hendriksen C, Kehlet H, et al. Outcomes in elderly Danish citizens admitted with communityacquired pneumonia. Regional differencties, in a public healthcare system. Respir Med. 2012;106(12):1778-87.

5. Statistics Denmark. Admissions by region, diagnosis (99 groups), age and sex, Denmark. http://www.statistikbanken.dk/statbank5a/default.asp?w=16 84. Assessed 1 Feb 2019

6. Christensen K, Doblhammer G, Rau R, Vaupel JW. Ageing populations: the challenges ahead. Lancet. 2009;374(9696):1196-208.

7. Danish Society of Infectious Diseases. Treatment of community-acquired pneumonia. 2011. http://www.infmed.dk/guidelines. Assessed 1 July 2016.

8. The Danish Diet \& Nutrition Association. The National Nutrition Handbook 2016 https://xn--kosthndbogen-xcb.dk/content/om-kosth\%C3\%A5ndbogen-0. Assessed 1 July 2016

9. The Danish Health Authority. Knowledge base: Nutritional interventions for the older medical patient. 2017. https://www.sst.dk/da/udgivelser/2017/ / media/3AD0A0709E57494EB8726B9D004CAE00.ashx. Assessed 1 April 2017.

10. Frølund JC, Klit M $\varnothing$, Ladegaard L, Lytjohan M, Mielcke H, Nielsen BE et al Clinical Guideline- Oral hygiene for adult citizens and patients 2016. http:// cfkr.dk/media/351666/Mundhygiejne\%20til\%20voksne\%20borgere\%20og\%2 Opatienter.pdf. Assessed 1 July 2016.

11. Danish Society of Respiratory Medicine. Guidelines for pneumonia - initial assessment and treatment. 2010. https://www.lungemedicin.dk/fagligt/71pneumoni.html. Assessed 1 july 2016.

12. Lim WS, Baudouin SV, George RC, Hill AT, Jamieson C, Le Jeune I, et al. BTS guidelines for the management of community acquired pneumonia in adults: update 2009. Thorax. 2009;64(Suppl 3):iii1-55.

13. Mandell LA, Wunderink RG, Anzueto A, Bartlett JG, Campbell GD, Dean NC, et al. Infectious Diseases Society of America/American Thoracic Society consensus guidelines on the management of community-acquired pneumonia in adults. Clin Infect Dis. 2007;44(Suppl 2):S27-72.

14. Woodhead M, Blasi F, Ewig S, Garau J, Huchon G, leven M, et al. Guidelines for the management of adult lower respiratory tract infections--full version. Clin Microbiol Infect. 2011;17(Suppl 6):E1-59.

15. O'Driscoll BR, Howard LS, Earis J, Mak V. British Thoracic Society guideline for oxygen use in adults in healthcare and emergency settings. BMJ Open Respir Res. 2017;4(1):e000170.

16. Lim W, Arnold DM, Bachanova V, Haspel RL, Rosovsky RP, Shustov AR, et al. Evidence-based guidelines--an introduction. Hematology Am Soc Hematol Educ Program. 2008:26-30.

17. Arnold FW, LaJoie AS, Brock GN, Peyrani P, Rello J, Menendez R, et al. Improving outcomes in elderly patients with community-acquired pneumonia by adhering to national guidelines: community-acquired pneumonia organization international cohort study results. Arch Intern Med. 2009;169(16):1515-24.

18. Lindhardt T, Klausen HH, Christiansen C, Smith LL, Pedersen J, Andersen O. Elderly patients with community-acquired pneumonia are not treated according to current guidelines. Dan Med J. 2013;60(2):A4572.

19. Mudge AM, O'Rourke P, Denaro CP. Timing and risk factors for functional changes associated with medical hospitalization in older patients. J Gerontol A Biol Sci Med Sci. 2010;65(8):866-72. 
20. Buurman BM, Hoogerduijn JG, de Haan RJ, Abu-Hanna A, Lagaay AM, Verhaar $\mathrm{HJ}$, et al. Geriatric conditions in acutely hospitalized older patients: prevalence and one-year survival and functional decline. PLoS One. 2011; 6(11):e26951.

21. Nilsen P. Making sense of implementation theories, models and frameworks. Implementation Sci. 2015;10:53

22. Grol R, Wensing M, Eccles M, Davis D. Improving Patient Care. In: The implementation of Change in Clinical Practice. 2nd ed: Wiley Blackwell BMJ Books: Edinburgh; 2013.

23. De Marinis MG, Piredda M, Pascarella MC, Vincenzi B, Spiga F, Tartaglini D, et al. 'If it is not recorded, it has not been done!'? Consistency between nursing records and observed nursing care in an Italian hospital. J Clin Nurs. 2010;19(11-12):1544-52.

24. The Capital Region of Denmark. Nursing assessment and recording. 2014. https://vip.regionh.dk/VIP/Admin/GUl.nsf/Desktop.html?open\&openlink= http://vip.regionh.dk/VIP/Slutbruger/Portal.nsf/Main.html?open\&unid=X575 9E812BA8099C9C12578AA002C8103\&level=1501\&dbpath=NIP/Redaktoer RH.nsf/\&windowwidth=1100\&windowheight=600\&windowtitle=S\%F8g. Assessed 1 April 2017.

25. Charlson ME, Pompei P, Ales KL, MacKenzie CR. A new method of classifying prognostic comorbidity in longitudinal studies: development and validation. J Chronic Dis. 1987;40(5):373-83.

26. Kristensen MT, Jakobsen TL, Nielsen JW, Jorgensen LM, Nienhuis RJ, Jonsson LR. Cumulated ambulation score to evaluate mobility is feasible in geriatric patients and in patients with hip fracture. Dan Med J. 2012;59(7):A4464.

27. Berg BL. Qualitative research methods for the social sciences. 4th ed. Boston: Allyn and Bacon; 2004.

28. Nadarajan P, Wilson L, Mohammed B, Connor M, Lane SJ. Compliance in the measurement of CURB-65 in patients with community acquired pneumonia and potential implications for early discharge. Ir Med J. 2008; 101(5):144-6.

29. Guo Q, Li HY, Zhou YP, Li M, Chen XK, Liu H, et al. Compliance with the CURB-65 score and the consequences of non-implementation. Int J Tuberc Lung Dis. 2011;15(12):1697-702.

30. Alyacoubi S, Abuowda Y, Albarqouni L, Bottcher B, Elessi K. Inpatient management of community-acquired pneumonia at the European Gaza Hospital: a clinical audit. Lancet (London, England). 2018;391(Suppl 2):S40.

31. Julian-Jimenez A, de los Reyes MJ P, Parejo Miguez R, Lain-Teres N, Cuenaboy R, Lozano-Ancin A. Improved management of community-acquired pneumonia in the emergency department. Arch Bronconeumol. 2013;49(6): 230-40.

32. Lee JS, Giesler DL, Gellad WF, Fine MJ. Antibiotic therapy for adults hospitalized with community-acquired pneumonia: a systematic review. Jama. 2016:315(6):593-602.

33. Torres A, Blasi F, Peetermans WE, Viegi G, Welte T. The aetiology and antibiotic management of community-acquired pneumonia in adults in Europe: a literature review. Eur J Clin Microbiol Infect Dis. 2014;33(7): 1065-79.

34. Gattarello S, Ramirez S, Almarales JR, Borgatta B, Lagunes L, Encina B, et al. Causes of non-adherence to therapeutic guidelines in severe communityacquired pneumonia. Rev Bras Ter Intensiva. 2015;27(1):44-50.

35. Egger ME, Myers JA, Arnold FW, Pass LA, Ramirez JA, Brock GN. Cost effectiveness of adherence to IDSA/ATS guidelines in elderly patients hospitalized for community-Aquired pneumonia. BMC Med Inform Decis Mak. 2016;16:34.

36. Galanter KM, Ho J. Impact of an empiric therapy guide on antibiotic prescribing in the emergency department. J Hosp Infect. 2019.

37. Wongsurakiat $P$, Chitwarakorn N. Severe community-acquired pneumonia in general medical wards: outcomes and impact of initial antibiotic selection. BMC Pulm Med. 2019;19(1):179.

38. Davey P, Marwick CA, Scott CL, Charani E, McNeil K, Brown E, Gould IM, Ramsay CR, Michie $S$. Interventions to improve antibiotic prescribing practices for hospital inpatients. Cochrane Database Syst Rev. 2017, Issue 2 Art. No.: CD003543. doi:https://doi.org/10.1002/14651858.CD003543.pub4.

39. Athanassa Z, Makris G, Dimopoulos G, Falagas ME. Early switch to oral treatment in patients with moderate to severe community-acquired pneumonia: a meta-analysis. Drugs. 2008;68(17):2469-81.

40. Oosterheert JJ, Bonten MJ, Schneider MM, Buskens E, Lammers JW, Hustinx WM, et al. Effectiveness of early switch from intravenous to oral antibiotics in severe community acquired pneumonia: multicentre randomised trial. BMJ (Clinical Res Ed). 2006;333(7580):1193.
41. Arancibia F, Ewig S, Martinez JA, Ruiz M, Bauer T, Marcos MA, et al. Antimicrobial treatment failures in patients with community-acquired pneumonia: causes and prognostic implications. Am J Respir Crit Care Med. 2000;162(1):154-60.

42. Yang M, Yan Y, Yin X, Wang BY, Wu T, Liu GJ, Dong BR. Chest physiotherapy for pneumonia in adults. Cochrane Database Syst Rev. 2013, Issue 2. Art. No.: CD006338. doi: https://doi.org/10.1002/14651858. CD006338.pub3.

43. Bally MR, Blaser Yildirim PZ, Bounoure L, Gloy VL, Mueller B, Briel M, et al. Nutritional support and outcomes in malnourished medical inpatients: a systematic review and meta-analysis. JAMA Intern Med. 2016;176(1):43-53.

44. Milano PK, Desai SA, Eiting EA, Hofmann EF, Lam CN, Menchine M. Sepsis bundle adherence is associated with improved survival in severe Sepsis or septic shock. West J Emerg Med. 2018;19(5):774-81.

45. Mundy LM, Leet TL, Darst K, Schnitzler MA, Dunagan WC. Early mobilization of patients hospitalized with community-acquired pneumonia. Chest. 2003; 124(3):883-9.

46. Sjogren $P$, Nilsson E, Forsell $M$, Johansson $O$, Hoogstraate J. A systematic review of the preventive effect of oral hygiene on pneumonia and respiratory tract infection in elderly people in hospitals and nursing homes: effect estimates and methodological quality of randomized controlled trials. J Am Geriatr Soc. 2008;56(11):2124-30.

47. Jones TL, Hamilton P, Murry N. Unfinished nursing care, missed care, and implicitly rationed care: state of the science review. Int J Nurs Stud. 2015; 52(6):1121-37.

48. Andrews J, Sathe NA, Krishnaswami S, McPheeters ML. Nonpharmacologic airway clearance techniques in hospitalized patients: a systematic review. Respir Care. 2013;58(12):2160-86.

49. Recio-Saucedo A, Dall'Ora C, Maruotti A, Ball J, Briggs J, Meredith P, et al. What impact does nursing care left undone have on patient outcomes? Review of the literature. J Clin Nurs. 2018;27(11-12):2248-59.

50. Ball JE, Bruyneel L, Aiken LH, Sermeus W, Sloane DM, Rafferty AM, et al. Post-operative mortality, missed care and nurse staffing in nine countries: a cross-sectional study. Int J Nurs Stud. 2018;78:10-5.

51. Hua F, Xie H, Worthington HV, Furness S, Zhang Q, Li C. Oral hygiene care for critically ill patients to prevent ventilator-associated pneumonia. Cochrane Database of Syst Rev. 2016, Issue 10. Art. No.: CD008367. doi: https://doi.org/10.1002/14651858.CD008367.pub3.

52. Guppy MPB, Mickan SM, Del Mar CB, Thorning S, Rack A. Advising patients to increase fluid intake for treating acute respiratory infections. Cochrane Database Syst Rev. 2011, Issue 2. Art. No.: CD004419. doi:https://doi.org/10. 1002/14651858.CD004419.pub3.

53. Simonetti AF, Viasus D, Garcia-Vidal C, Carratala J. Management of community-acquired pneumonia in older adults. Ther Adv Infect Dis. 2014; 2(1):3-16.

54. Juthani-Mehta M, De Rekeneire N, Allore H, Chen S, O'Leary JR, Bauer DC, et al. Modifiable risk factors for pneumonia requiring hospitalization of community-dwelling older adults: the health, aging, and body composition study. J Am Geriatr Soc. 2013;61(7):1111-8.

55. Carratala J, Garcia-Vidal C, Ortega L, Fernandez-Sabe N, Clemente M, Albero $\mathrm{G}$, et al. Effect of a 3-step critical pathway to reduce duration of intravenous antibiotic therapy and length of stay in community-acquired pneumonia: a randomized controlled trial. Arch Intern Med. 2012;172(12):922-8.

56. Griffiths P, Recio-Saucedo A, Dall'Ora C, Briggs J, Maruotti A, Meredith P, et al. The association between nurse staffing and omissions in nursing care: a systematic review. J Adv Nurs. 2018;74(7):1474-87.

57. Jordan J, Rose L, Dainty KN, Noyes J, Blackwood B. Factors that impact on the use of mechanical ventilation weaning protocols in critically ill adults and children: a qualitative evidence-synthesis. Cochrane Database Syst Rev 2016, Issue 10. Art. No.: CD011812. doi: https://doi.org/10.1002/14651858. CD011812.pub2.

58. Francke AL, Smit MC, de Veer AJ, Mistiaen P. Factors influencing the implementation of clinical guidelines for health care professionals: a systematic meta-review. BMC Med Inform Decis Mak. 2008;8:38.

59. Aiken LH, Sloane DM, Bruyneel L, Van den Heede K, Griffiths P, Busse R, et al. Nurse staffing and education and hospital mortality in nine European countries: a retrospective observational study. Lancet (London, England). 2014;383(9931):1824-30.

60. Needleman J, Liu J, Shang J, Larson EL, Stone PW. Association of registered nurse and nursing support staffing with inpatient hospital mortality. BM Qual Saf. 2019. 
61. Francis JJ, O'Connor D, Curran J. Theories of behaviour change synthesised into a set of theoretical groupings: introducing a thematic series on the theoretical domains framework. Implement Sci. 2012;7:35.

62. Taylor SL, Dy S, Foy R, Hempel S, McDonald KM, Ovretveit J, et al. What context features might be important determinants of the effectiveness of patient safety practice interventions? BMJ Gual Saf. 2011;20(7):611-7.

63. Baker R, Camosso-Stefinovic J, Gillies C, Shaw EJ, Cheater F, Flottorp S, Robertson N. Tailored interventions to overcome identified barriers to change: effects on professional practice and health care outcomes. Cochrane Database Syst Rev. 2010, Issue 3. Art. No.: CD005470. doi: https:// doi.org/10.1002/14651858.CD005470.pub2.61.

64. Flick U. Managing quality in qualitative research. California: SAGE Publications; 2007.

65. World Medical Association Declaration of Helsinki: ethical principles for medical research involvng human subjects. J Am Coll Dent. 2014;81(3):14-8.

\section{Publisher's Note}

Springer Nature remains neutral with regard to jurisdictional claims in published maps and institutional affiliations.

Ready to submit your research? Choose BMC and benefit from:

- fast, convenient online submission

- thorough peer review by experienced researchers in your field

- rapid publication on acceptance

- support for research data, including large and complex data types

- gold Open Access which fosters wider collaboration and increased citations

- maximum visibility for your research: over $100 \mathrm{M}$ website views per year

At BMC, research is always in progress.

Learn more biomedcentral.com/submissions 